\title{
Editorial
}

https://doi.org/10.11646/megataxa.1.1.1

\section{Megataxa for big science questions in taxonomy}

\author{
ZHI-QIANG ZHANG ${ }^{1,2}$ \\ ${ }^{1}$ Manaaki Whenua - Landcare Research, 231 Morrin Road, Auckland, New Zealand; !"'zhangz@landcareresearch.co.nz; \\ (1) https://orcid.org/0000-0003-4172-0592 \\ ${ }^{2}$ Centre for Biodiversity \& Biosecurity, School of Biological Sciences, University of Auckland, Auckland, New Zealand
}

I am delighted to announce the inaugural issue of Megataxa, a new journal designed for large monographic reviews and highly significant original papers reporting major advances in taxonomy. Megataxa aims to be a premium journal of high impact to encourage most important works in taxonomy. As a general journal of taxonomy, Megataxa will also include an editorial/ correspondence section to allow announcements of major news, debates of highly significant issues, theory/method papers of general taxonomic significance, and biographic profiles for recently passed eminent taxonomists.

Megataxa will focus particularly on big science questions in biology that are taxonomic in nature and essence. Like its sister journals, Zootaxa and Phytotaxa, Megataxa strives to accelerate the documentation of undescribed species (Christenhusz et al. 2009; Zhang et al. 2011) in this age of rapid extinction (Barnosky et al. 2011; Ceballos et al. 2015). It will increase efficiency by encouraging collaborative teamwork at a large scale to take advantage of economies of scale. From the outset, Megataxa will feature two series of mega-papers with the main titles "Toward a million new species" and "All genera of the world".

"Toward a million new species" will accept large collaborative papers having at least 100 new species each, with a focus on hyper-rich taxa such as invertebrates and fungi (e.g. Lumbsch et al. 2011). Communities of taxonomists can propose large projects to be published in this series. It will also accept large papers describing over 100 new species by individual authors or small teams.

The "All genera of the world" series invites large manuscripts each with a full list of all genera of a large taxon in a currently accepted consensus higher classification, including species richness, type species and synonyms (if any) of each genus. These can be by individual authors or a large team; the latter is preferred as it allows participation of many taxonomists and can be completed faster. This series will provide foundations for a full inventory of life on earth.
In preparation for this inaugural issue, I asked 22 taxonomists what they think are the top three questions or challenges in taxonomy today. These taxonomists represent a broad range of backgrounds: a young graduate student and several retired professors, taxonomists from both developed and developing countries, and specialists working on a diversity of taxa (e.g. fungi, plants, annelids, crustaceans, myriapods, spiders, wasps, flies, hemipterans, reptiles, and amphibians). This inaugural issue presents a collection of 15 papers on the top three questions/challenges in taxonomy from their perspective. In addition to the urgent task of describing new species and completing a full inventory of life on earth (Orr et al. 2020; Lücking 2020; Prathapan \& Rajan 2020; Wheeler 2020), many authors agreed on the importance of developing taxonomic capacity through training and mentoring future generations of taxonomists - especially in biodiversity-rich developing countries (Borkent 2020; Britz et al. 2020; Coleman \& Radulovici 2020; Hutchings 2020; Orr et al. 2020; Prathapan \& Rajan 2020) —as well as the urgent need to address the decline in funding for taxonomy and the loss of taxonomic positions in museums, universities, and other institutions (Borkent 2020; Britz et al. 2020; Dupérré 2020; Hutchings 2020). For taxonomy to thrive, it is important to integrate traditional taxonomy with other branches of modern science and technology, e.g. molecular biology, information science, big data/ AI, engineering, entrepreneurialism (Borkent 2020; Boxshall 2020; Longino 2020; Lücking 2020; Orr et al. 2020; Saunders 2020; Vences 2020; Wheeler 2020). It is necessary to redefine taxonomy and communicate its values to the broader society (Borkent 2020; Boxshall 2020; Christenhusz 2020; Dupérré 2020; Hutchings 2020; Lücking 2020; Saunders 2020; Wheeler 2020). Several authors also emphasised an urgent need to revise nomenclatural rules to deal with provisionally circumscribed taxa (Minelli 2020), cryptic diversity (Longino 2020), descriptions based on molecular data (Dupérré 2020), and stable nomenclature for phylogenetic 
classification (Christenhusz 2020). Other important issues discussed include developing and maintaining taxonomic databases (Boxshall 2020; Coleman \& Radulovici 2020; Prathapan \& Rajan 2020), pluralism in taxonomy (Minelli 2020), the impact of extinction (Borkent 2020), species concepts and delimiting/naming species (Christenhusz 2020; Longino 2020), and the negative effects of Nagoya Protocol and permits (Britz et al. 2020; Lücking 2020; Prathapan \& Rajan 2020).

Megataxa will be linked with a new international, yet to be named society (e.g. "International Union of Taxonomists") whose mission will be to promote taxonomy, facilitate collaboration among taxonomists, and increase the impact of taxonomy. Membership is via in-kind contributions as authors, reviewers, and editors of the journal. Others can participate via in-kind support or the payment of a membership fee. Megataxa is a sister journal of Zootaxa and Phytotaxa and will allow manuscript transfer to and from each of these journals. It will be published in a continuous model as Zootaxa and Phytotaxa (Zhang 2014). Megataxa is a GOLD open access journal with free online access for all. Author contributions of a publication processing fee are needed for publication, but discounts will be provided to authors in need and waivers granted for those without funds on a case-by-case basis.

\section{Acknowlegments}

I thank Anne Austin (Manaaki Whenua-Landcare Research, Palmerston North) for editorial assistance. I also thank authors of papers in this issue for their contributions and reviewers for their comments in a timely manner.

\section{References}

Barnosky, A.D., Matzke, N., Tomiya, S., Wogan, G.O.U., Swartz, B., Quental, T.B., Marshall, C., McGuire, J.L., Lindsey, E.L., Maguire, K.C., Mersey, B. \& Ferrer, E.A. (2011) Has the Earth's sixth mass extinction already arrived? Nature, 471, 51-57. https://doi.org/10.1038/nature09678

Borkent, A. (2020) Shrinking biodiversity, dwindling taxonomy and building a broader science. Megataxa, 1 (1), 53-58. https://doi.org/10.11646/megataxa.1.1.11

Boxshall, G.A. (2020) Self-help for taxonomists: three things we must do for taxonomy to survive. Megataxa, 1 (1), 39-42. https://doi.org/10.11646/megataxa.1.1.7

Britz, R., Hundsdörfer, A. \& Fritz, U. (2020) Funding, training, permits - the three big challenges of taxonomy. Megataxa, 1 (1), 49-52.

https://doi.org/10.11646/megataxa.1.1.10

Ceballos, G., Ehrlich, P.R., Barnosky, A.D., García, A., Pringle, R.M. \& Palmer, T.M. (2015) Accelerated modern human- induced species losses: Entering the sixth mass extinction. Science Advances, 1, 5, e1400253.

https://doi.org/10.1126/sciadv.1400253

Coleman, C.O. \& Radulovici, A.E. (2020) Challenges for the future of taxonomy: talents, databases and knowledge growth. Megataxa, 1 (1), 28-34.

https://doi.org/10.11646/megataxa.1.1.5

Christenhusz, M.J.M. (2020) On species concepts, phylogenetics and the science of natural history-three current questions facing taxonomy. Megataxa, 1 (1), 67-72. https://doi.org/10.11646/megataxa.1.1.14

Christenhusz, M.J.M., Chase, M.W., Fay, M.F., Lumbsch, T., Monro, A., Vorontsova, M. \& Zhang, Z.-Q. (2009) A new international journal for rapid publication of botanical taxonomy. Phytotaxa, 1, 1-2.

https://doi.org/10.11646/phytotaxa.1.1.1

Dupérré, N. (2020) Old and new challenges in taxonomy: what are taxonomists up against? Megataxa, 1 (1), 59-62.

https://doi.org/10.11646/megataxa.1.1.12

Hutchings, P. (2020) Major issues facing taxonomy-a personal perspective. Megataxa, 1 (1), 46-48.

https://doi.org/10.11646/megataxa.1.1.9

Longino, J.T. (2020) Navigating the Ship of Theseus from typology to cartography. Megataxa, 1 (1), 43-45. https://doi.org/10.11646/megataxa.1.1.8

Lücking, R. (2020) Three challenges to contemporaneous taxonomy from a licheno-mycological perspective. Megataxa, 1 (1), 78-103.

https://doi.org/10.11646/megataxa.1.1.16

Lumbsch, H.T., Ahti, T., Altermann, S., De Paz, G.A., Aptroot, A., Arup, U., Pena, A.B., Bawingan, P.A., Benatti, M.N., Betancourt, L., Bjork, C.R., Boonpragob, K., Brand, M., Bungartz, F., Caceres, M.E.S., Candan, M., Chaves, J.L., Clerc, P., Common, R., Coppins, B.J., Crespo, A., DalForno, M., Divakar, P.K., Duya, M.V., Elix, J.A., Elvebakk, A., Fankhauser, J.D., Farkas, E., Ferraro, L.I., Fischer, E., Galloway, D.J., Gaya, E., Giralt, M., Goward, T., Grube, M., Hafellner, J., Hernandez, J.E., Campos, M.D.H., Kalb, K., Karnefelt, I., Kantvilas, G., Killmann, D., Kirika, P., Knudsen, K., Komposch, H., Kondratyuk, S., Lawrey, J.D., Mangold, A., Marcelli, M.P., Mccune, B., Messuti, M.I., Michlig, A., Gonzalez, R.M., Moncada, B., Naikatini, A., Nelsen, M.P., Ovstedal, D.O., Palice, Z., Papong, K., Parnmen, S., PerezOrtega, S., Printzen, C., Rico, V.J., Plata, E.R., Robayo, J., Rosabal, D., Ruprecht, U., Allen, N.S., Sancho, L., De_Jesus, L.S., Vieira, T.S., Schultz, M., Seaward, M.R.D., Serusiaux, E., Schmitt, I., Sipman, H.J.M., Sohrabi, M., Sochting, U., Sogaard, M.Z., Sparrius, L.B., Splielmann, A., Spribille, T., Sutjaritturakan, J., Thammathaworn, A., Thell, A., Thor, G., Thus, H., Timdal, E., Truong, C., Turk, R., Tenorio, L.U., Upreti, D.K., Van den Boom, P., Rebuelta, M.V., Wedin, M., Will-Wolf, S., Wirth, V., Wirtz, N., Yahr, R., Yeshitela, K., Ziemmeck, F., Wheeler, T. \& Lucking, R. (2011) One hundred new species of lichenized fungi: a signature of undiscovered global diversity. Phytotaxa, 18, 1-127. https://doi.org/10.11646/phytotaxa.18.1.1

Minelli, A. (2020) Taxonomy needs pluralism, but a controlled and manageable one. Megataxa, 1 (1), 9-18. https://doi.org/10.11646/megataxa.1.1.3

Orr, M.C., Ascher, J.S., Bai, M., Chesters, D. \& Zhu, C.-D. (2020) Three questions: How can taxonomists survive and thrive worldwide? Megataxa, 1 (1), 19-27.

https://doi.org/10.11646/megataxa.1.1.4 
Prathapan, K.D. \& Rajan, P.D. (2020) Advancing Taxonomy in the Global South and completing the Grand Linnaean Enterprise. Megataxa, 1 (1), 73-77.

https://doi.org/10.11646/megataxa.1.1.15

Saunders, T.E. (2020) Taxonomy at a crossroads: Communicating value, building capability, and seizing opportunities for the future. Megataxa, 1 (1), 63-66.

https://doi.org/10.11646/megataxa.1.1.13

Vences, M. (2020) The promise of next-generation taxonomy. Megataxa, 1 (1), 35-38.

https://doi.org/10.11646/megataxa.1.1.6
Wheeler, Q. (2020) A taxonomic renaissance in three acts. Megataxa, 1 (1), 4-8.

https://doi.org/10.11646/megataxa.1.1.2

Zhang, Z.-Q. (2011) Accelerating biodiversity descriptions and transforming taxonomic publishing: the first decade of Zootaxa. Zootaxa, 2896, 1-7.

https://doi.org/10.11646/zootaxa.2896.1.1

Zhang, Z.-Q. (2014) Sustaining the development of world's foremost journal in biodiversity discovery and inventory: Zootaxa editors and their contributions. Zootaxa, 3753 (6), 597-600.

https://doi.org/10.11646/zootaxa.3753.6.6 